\title{
COMMUNICATION FORUM
}

\section{Commentary}

In this second article on the Analytical Writing Assessment (AWA), a new component in the Graduate Management Admission Test (GMAT), we analyze the AWA's contribution as a performance assessment and critique its potential usefulness as a diagnostic tool for management education. The AWA assesses writing as a high-level ability and thereby challenges its marginalization as a low-level skill in MBA programs. Holistic evaluation, which makes performance assessment of writing possible, however, cannot provide diagnostic information. Therefore, the AWA does not meet the expectations of GMAT-user schools who endorsed the test as a diagnostic instrument for identifying individual deficiencies. If business schools wish to determine students' needs for further work in writing, they must evaluate the essays locally. Ironically, this task may prove too costly for those schools enrolling students most in need of the diagnostic information.

\section{WHAT IS THE FUNCTIONAL VALUE OF THE GMAT ANALYTICAL WRITING ASSESSMENT FOR MANAGEMENT EDUCATION? A Critical Analysis, Part 2}

\author{
Priscilla S. Rogers \\ University of Michigan \\ Jone Rymer \\ Wayne State University
}

The Graduate Management Admission Council's (GMAC) introduction of the Analytical Writing Assessment (AWA) into the Graduate Management Admission Test (GMAT) ${ }^{1}$ places those involved with management education at a critical juncture. Hundreds of GMAT-subscribing schools will receive writing assessment

AUTHORS' NOTE: We contributed equally to this article and have listed our names in alphabetical order.

Management Communication Quarterly, Vol. 8, No. 4, May 1995 477-494

(C) 1995 Sage Publications, Inc. 
scores and essays for thousands of MBA applicants from all over North America and from many other countries, especially in Western Europe and in Asia; these test results will influence admissions, placement, and program decisions nationwide. Management educators will have to determine whether they should use the results of this new writing test, and if so, how; they must also consider the test's ramifications for MBA programs and, perhaps most significantly, its implications for management communications. ${ }^{2}$ The AWA raises a surprising number of important diagnostic and curricular questions, including the following:

- How useful is the GMAT writing test for MBA programs? Should the AWA results inform MBA student-placement decisions? Should students with low scores be provided with special courses or tutoring? Should students with high scores be granted waivers of communication requirements?

- Should business curricula be altered based on AWA scores of a program's entering students? Should current communication courses be modified or local writing assessments be eliminated? Should new communication courses be furnished to meet student needs identified by the AWA?

As business school administrators and faculty address these and other questions, the new GMAT test will influence the perceptions and practices of written communication in business school curricula. On the one hand, as a performance assessment the AWA may call attention to writing as a high-level, significant management competency, increasing its role in the overall MBA curriculum and creating demand for new courses emphasizing writing. On the other hand, as a diagnostic instrument, the AWA may prompt curricular modifications, such as the elimination of local assessments and the introduction of remedial offerings, perhaps in lieu of established communication courses, particularly at schools facing budget constraints. The GMAT analytical writing test does, indeed, place management educators at a critical juncture, a juncture that is yet little understood. 
In this second of a two-part critique of the AWA, we appraise the GMAT writing test's potential impact on MBA programs. After describing the conceptual significance of the AWA, we analyze the AWA's value as a tool for diagnosing MBA students' needs for further work in writing, comparing the results the AWA will yield with the expectations management educators expressed when they endorsed the new test. We conclude by suggesting some possible ramifications of the new writing test for MBA programs.

Our analysis in Part 1 showed that as a performance assessment, the AWA is conceptually rich, defining writing as a highly complex, cognitive activity, one that serves the test's primary function as a new component in the admissions process (Rogers \& Rymer, 1995). As a diagnostic tool, however, the AWA is limited. Counter to what GMAC promotional materials imply, the new test will not readily fulfill its announced secondary function to serve as a diagnostic instrument; the AWA scores provide no specific information on students' individual writing abilities or their particular needs for further work in writing. All in all, the AWA confronts business school faculty and administrators with significant questions regarding interpretation of the AWA scores, whether and how to evaluate the AWA essays locally, and what consequences these decisions will have upon the place of writing in management education. Communication faculty can expect that the AWA will create more opportunities and responsibilities for their expertise, but whether as full collegial partners in developing the higher-order abilities of management students or as instructors for service courses and tutors for remediation is still unclear. Given the significance of the decisions involved, management educators need to become knowledgeable about the usefulness and the limitations of the AWA if they are to foster an accurate understanding of the new test and its appropriate application in their programs, to respond to new demands by MBA administrators, and, more important, to participate in the conversation initiated by the new test, a conversation that will help shape the future of written communication in management education. 


\section{WHAT IS THE CONCEPTUAL SIGNIFICANCE OF THE GMAT ANALYTICAL WRITING ASSESSMENT?}

Perhaps the most significant contribution of the GMAT Analytical Writing Assessment (AWA) stems from the fact that it is a performance-based assessment, a test that by its nature defines writing as a high-level, multifaceted ability. Part of the educational trend toward accountability and evaluation of competency through performance, the AWA requires test takers to demonstrate ability to write by writing, instead of by merely answering questions about writing. To complete the AWA, test takers must compose two essays "from scratch," a task that involves inventing ideas and formulating plans; developing and organizing content; and drafting, revising, and editing paragraphs, sentences, and words. In short, the AWA requires a wide range of cognitive abilities, procedural knowledge of composing, and many language and textual skills, including grammar and mechanics.

As a performance assessment or direct test of writing, the AWA contrasts with objective or indirect tests, such as the GMAT Verbal section. Although indirect tests posing multiple-choice questions have traditionally been used to assess writing ability, such tests do not actually evaluate writing per se. Instead, they measure passive or "declarative" knowledge of reading ability and some skills that contribute to writing ability, especially sentence-level skills such as diction, syntax, usage, and conventions of Standard Written English. Although indirect tests are inexpensive, reliable, and easy to administer, and although the best of them correlate reasonably with direct tests of writing, research shows that they do not test the same competencies as performance writing tests, nor do they sample the full range of abilities involved in writing (Camp, 1993). More significant, they send misleading signals about the value and nature of writing ability. Rather than confronting test takers with the complexities involved in actually composing text, indirect tests confront test takers with lower-level textual tasks, such as questions on usage, style, and identification of errors in grammar and mechanics (Faigley, Cherry, Jolliffe, \& Skinner, 1985). ${ }^{3}$ Therefore, indirect tests have largely been supplemented or replaced at all 
educational levels by direct tests of writing (White, 1993, 1994; Williamson, 1993). ${ }^{4}$ Most national admissions tests, including graduate tests such as the Medical College Admission Test (MCAT) and the Law School Admission Test (LSAT), now include performance tests of writing, and soon the Graduate Record Examination (GRE) will as well. ${ }^{5}$ Existing large-scale performance tests of writing created a favorable environment for adding the AWA to the GMAT, and they established model methods and practices that strongly influenced the AWA's design and development.

Large-scale performance assessments of writing-by nature, cumbersome, time-consuming, and costly-became possible through the development of holistic scoring. Derived from the theory that writing is a meaning-making activity, not a set of discrete skills, holistic scoring appraises whole discourse, say an essay or a memorandum, and emphasizes the wholeness or unity of a text as being of greater significance than its individual parts, such as its style, organization, and tone (White, 1994). Rather than isolating and evaluating pieces or individual components of a text (or the various subskills a writer displays), holistic evaluators read a text as a whole and assign a single score reflecting its overall quality. In addition to being efficient, this global, single score reflects a more comprehensive theory about written communication.

By refining holistic scoring procedures over many years, testing experts eventually achieved acceptable levels of agreement among evaluators, making it possible to score texts consistently, even for large-scale assessments. Evaluators learn to develop a holistic score by attending to some features and ignoring others, as specified by the assessment criteria (e.g., in the AWA, evaluators observe syntax and diction, but not style or tone). Evaluators do not score the specified features separately, but notice them as they read, considering the extent to which a writer demonstrates mastery of them in the text as a whole. By the 1980s this holistic scoring method had enabled performance assessment of writing to become a sufficiently reliable and reasonably economical enterprise so that when GMAC confronted the issue in 1992, it presented a feasible testing option for the GMAT (see White, 1994; Williamson, 1993). ${ }^{6}$ 
Although it is not the first direct test of writing in management education, the new GMAT writing test is the only international (or even national) performance assessment of writing for management education; because it involves about 200,000 MBA applicants annually, it will inevitably become the most influential. Local writing performance assessments have been administered for some time at the Stern School of Business at New York University and at the University of Michigan School of Business Administration, which have served as models for programs at other schools (such as the David Eccles School of Business at the University of Utah). (Recently, the Harvard Business School also introduced an assessment.)

Although long-standing local performance assessments have been successfully integrated into some MBA programs, these writing tests are not widely known nor have they become a standard component in management communication training nationwide. Adding the AWA to the GMAT makes available to all MBA programs at least some of the benefits previously enjoyed only by schools with the resources and the commitment necessary to provide local tests. Most significant, adding the AWA to the wellknown international GMAT brings performance assessment and the value it attaches to writing to the attention of all the participants in MBA programs. In effect, the AWA challenges the low-level skills orientation toward writing reflected in most MBA curricula (see Rogers \& Rymer, 1994).

\section{HOW EFFECTIVE IS THE GMAT ANALYTICAL WRITING ASSESSMENT AS A DIAGNOSTIC INSTRUMENT?}

According to a GMAC (n.d.) brochure on the AWA, the new writing test is useful as "a diagnostic aid for determining whether prospective and accepted students need specific work to develop communication skills" (p. 1). In other words, in addition to aiding the admissions process, GMAC suggests that the AWA can facilitate diagnostic decisions, such as directing students to tutorial services, communication workshops, and courses, or identifying 
students for whom communication requirements could be waived. GMAC's survey results suggest that GMAT-using schools registered strong support for the writing test because of its value as a diagnostic tool, with $62 \%$ endorsing the test as "very useful" for "determining the student's need for additional work in written communications," specifically "as a diagnostic instrument that would be useful in advising and course placement" (Bruce, 1993, pp. 10, 23). The diagnostic usefulness of the AWA is limited, however, both by the nature of the test itself - a large-scale, holistic performance assessment - and by the functional application of the test results.

Although the AWA provides holistic scores useful for admissions decisions, these scores are inadequate for diagnosing students' needs for further work in writing. Indeed, assessment scholars have long insisted that the holistic score is too general to be useful for diagnosis (White, 1993), and many have advocated combining holistic scoring with other ratings that are appropriate for placement (Quellmalz, 1984). Holistic scoring facilitates the testing of writing as a high-level, complex ability; it was never intended to provide specific information for diagnosing an individual's particular writing problems. Ironically, while holistic scoring enables the AWA to fulfill GMAC's first objective-to facilitate MBA admissions decisions - it inhibits the AWA from fulfilling GMAC's second goal-to serve as a diagnostic instrument for identifying individual deficiencies in writing. In short, diagnostic decisions simply cannot be made on the basis of holistic scores, including those provided by the GMAT writing test.

Certainly, many business schools may assume that the AWA scores can be used to diagnose individual students' writing needs, especially since GMAC's publications state unequivocally that the AWA is a diagnostic aid (GMAC, n.d., p. 1). In fact, assessing applicants' writing deficiencies depends on a review of the essays themselves; diagnosing their communication needs cannot be based on the AWA scores alone. Reviewing the essays, however, requires a commitment of money, time, and expertise from individual schools-a commitment that administrators and other survey respondents may not have anticipated when endorsing the new test. 
But if schools decide to mount such an effort, how might they proceed? What would a local review of the essays involve? What cautions should be exercised and what procedures should be put in place for such efforts? To address these questions, we examine the AWA scores and essays that GMAC provides to business schools and suggest some of the complexities involved in interpreting them for diagnostic purposes.

\section{INTERPRETING THE AWA SCORES}

For each MBA applicant, schools receive a single AWA score, ranging from a low of 1 to a high of 6 (e.g., AWA 4.5). The AWA score is an average of the holistic scores awarded to each of the two essays (rounded to the nearest half-point interval). ${ }^{7}$ A test evaluator awards a single holistic score to reflect the overall quality of the writing based on the specific features established by the test criteria. However, because evaluators consider multiple features when awarding a holistic score, "responses receiving the same score may differ in approach or in the particular mix of writing features" (GMAC, n.d., p. 7); that is, any two essays receiving scores of 4 will not necessarily have similar strengths and weaknesses. Therefore, making diagnostic decisions solely on the basis of AWA scores would be highly problematic because essays receiving any single score manifest different deficiencies and thus different writing problems of the test takers. A low AWA score only suggests that a prospective student has one or more of several possible problems of some severity. Thus if schools want to use the AWA scores as the sole screening device for placement decisions, they should be aware that all those individuals scoring below a certain level come with highly diverse needs for further work in writing, needs that cannot be met simply through a standardized remedial course or workshop.

To assist schools in interpreting the AWA results, GMAC furnishes the AWA scoring guide designating the characteristics of essays at each scoring level, as well as sample essays manifesting some of those characteristics (GMAC, n.d., pp. 11-15; GMAC, 1994). Applying the test results locally involves reviewing the AWA 
scoring guide and the sample essays as the basis for determining what score on the 6-point scale constitutes an acceptable level of performance for the specific MBA program. ${ }^{8}$ Much as with the traditional GMAT scores, administrators will likely determine an AWA cutoff score appropriate for admission to their programs, a score that could also serve as a benchmark for making diagnostic decisions for communication course placement and remedial work. However, implementing diagnostic decisions on the basis of an AWA cutoff score would result in only rough estimations of student needs-estimations that may be misleading, particularly to those without expertise in writing pedagogy. As already suggested, those students below any selected cutoff score on the AWA could include:

- Relatively sophisticated writers with problems in controlling surface errors

- Non-native speakers with language-specific learning needs, say Chinese students struggling with English

- Students who write "correctly" according to Standard English but do not understand how to develop their ideas or organize effectively

- Students who have major problems with coherence and basic logic.

Admittedly, these students' needs might be met if a school were to establish very small classes under experienced instructors who could attend to the individual needs of students with highly diverse writing deficiencies. If such small classes or even tutorials represent a feasible option for an MBA program, then the AWA cutoff scores may prove useful to refer students to individualized instruction. Otherwise, appropriate and accurate use of the AWA results for diagnostic purposes in local contexts-which are far removed from the original evaluation process-requires a careful analysis of the essays by local personnel who have the necessary expertise. Although the AWA evaluators observe specific features as the basis for their holistic judgments of individual essays, they do not record the details of their analysis or mark the essays in any way. Consequently, when schools receive photocopies of students' unmarked essays, it is impossible to determine what specific strengths or weaknesses influenced the AWA score without reading and analyzing the essays anew. 


\section{EVALUATING THE AWA ESSAYS}

If MBA programs want to diagnose students' deficiencies in order to place them appropriately in one of several instructional options, or if they want to counsel students about their writing, suggesting how they might go about developing their writing abilities, schools must establish a careful evaluation process to match local opportunities for further work in writing (Smith, 1993). Because locally hired and trained evaluators would be aware of the options and appropriate placements for students exhibiting particular writing problems, such an in-house analysis of the AWA essays could be very effective. Indeed, as some MBA assessment programs have already shown, giving each student an opportunity to review his or her writing test with a local evaluator can furnish meaningful feedback as the basis for setting goals and selecting courses to develop needed communication competencies (Rogers, 1994). In this way, the writing assessment becomes a key component in a "set of contextualized experiences" designed for the teaching of writing (Camp, 1993, p. 63). Moreover, such review of the essays would allow MBA programs to meet the expectations of new students who-after expending time and money to write the AWA-would likely want their writing problems to be specified, especially if they received low AWA scores.

By furnishing the applicants' essays to the business schools, GMAC wisely deferred diagnostic issues to local personnel who are in the best position to make such decisions, and in so doing, minimized costs to test takers. ${ }^{9}$ Business schools-especially the majority of schools that endorsed the test primarily for its diagnostic function (Bruce, 1993)-may be surprised, however, that the AWA test results, in and of themselves, provide so little diagnostic information.

GMAC survey results showed significant differences between highly competitive elite programs, which perceived the usefulness of the AWA to be for admissions, and the "mainstream" business schools, which perceived the test's usefulness to be for diagnostic purposes. ${ }^{10}$ Mainstream schools, with lower entrance requirements than elite schools, inevitably enroll some students with academic deficiencies, including some with serious writing problems. Ac- 
cording to GMAC's survey, many of these mainstream MBA programs seem to have considered the GMAT writing test as an opportunity to help entering students improve their communication skills. However, mainstream schools are less likely than elite schools to have either the desire or the resources necessary to evaluate the AWA essays, especially because falling MBA enrollments affect them disproportionately and may discourage them from erecting any new barriers to potential students. Unless these schools can muster the commitment and the resources to do the job, the AWA will represent a lost opportunity to improve MBA students' academic writing. Such schools might admit low-scoring applicants with a requirement that they register for remedial work in writing, or they might simply admit such applicants without any proviso that they improve their writing abilities. If schools do nothing in response to the AWA scores, applicants who score poorly on the GMAT writing test will receive a clear message: You don't write well, but it doesn't matter. In effect, adding the AWA, as a separate component to the GMAT, confronts schools with a choice: Do something about the AWA or risk producing graduates who believe that their ineffective writing abilities will not affect their careers.

In providing business schools with applicants' AWA scores and photocopies of their essays, GMAC makes it abundantly clear that interpretation of both the scores and the essays is strictly a local matter (GMAC, n.d., p. 9). However, the GMAC promotional materials announce the diagnostic purpose for the writing test without clearly identifying the AWA essays as the appropriate diagnostic tool. Indeed, GMAC's publications are silent about the ramifications of using the AWA as a diagnostic instrument and give no indication that, without reviewing the essays, schools' diagnostic decisions would be only approximations. Nor does GMAC suggest the considerable costs individual MBA programs would incur if they did set out to evaluate the AWA essays for diagnostic purposes.

Overall, the new GMAT writing component absorbs considerable resources and creates high expectations for all GMATsubscribing schools, but it mainly satisfies the needs of the "top" 
schools that supported the AWA as a new admissions tool. For mainstream schools and other noncompetitive programs that endorsed the AWA test to facilitate placement decisions, and especially for those schools concerned about counseling individual students and offering them appropriate further work in writing, the AWA results provide little guidance.

\section{WHAT ARE THE RAMIFICATIONS OF THE AWA FOR MBA PROGRAMS?}

The potential impact of the AWA and the concerns raised by its introduction place management educators at a critical juncture. As part of the long-established GMAT and as a test developed by the Educational Testing Service (ETS), the AWA could easily become regarded as a standard for writing competency in management graduate study and its results applied injudiciously. Its endorsement by deans and MBA program directors indicates its perceived relevance to management education. A provocative addition to the GMAT, the AWA already has motivated dialogue between faculty and administrators about possible changes in MBA programs, with ideas ranging from the development of innovative courses and workshops to the modification or even elimination of existing offerings-all based on assumptions about the new writing test, many of which (as we have suggested) are erroneous. As we know from research, large-scale assessments of this kind can have "powerful, and often deleterious, effects . . . on teaching and curriculum" (Murphy, 1994, p. 177; see Huot \& Yancey, 1994). Reactions to the advent of the AWA and discussions in progress about possible MBA program changes suggest that this observation applies to the AWA and the business schools it was intended to serve (Rogers \& Rymer, 1994).

Conversation among all the constituencies of the management education community-deans and administrators, faculty, students, businesses, and organizations hiring MBAs-is essential to develop full awareness of the AWA's opportunities and its limitations so that schools can appropriately incorporate the test into the 
educational experience of management students. For example, even seemingly straightforward applications, such as faculty use of AWA essays as classroom examples or student use of high AWA scores as a kind of "certification" of communication competency for prospective employers, merit forethought because the AWA tests a kind of writing that is markedly different, not only from the writing taught in management communication classes, but also from the real-world writing practiced by managers in the workplace (see Rogers \& Rymer, 1995). Exploring the differences between the academic writing tested by the AWA and the writing required of MBA students and managers in light of national and local educational goals, student needs, and business requirements could be advantageous for all the constituencies involved.

Moreover, in this period of diminishing resources and decreasing enrollments, there may be pressures to effect large programmatic changes in response to the AWA. Such changes should be considered cautiously. Some schools, for example, may view the AWA as a replacement for local MBA writing assessments. But schools should not assume that the AWA fulfills the same objectives as MBA assessments. Through the use of case prompts involving elaborated business scenarios, MBA assessments test rhetorical and social aspects of writing pertinent to some writing practiced in management courses and to discourse taught in management communication classes. Most significant, the writing tested in MBA assessments is relevant to managerial writing in the workplace, which the AWA is not. ${ }^{11}$ In attempting to reflect real-world writing tasks, MBA assessments are certainly closer to what some have characterized as "authentic assessment" (Black, Helton, \& Sommers, 1994). As we have argued in the first part of this critique (Rogers \& Rymer, 1995), the choice of an analytical writing task for the GMAT severely limits the relevance of the AWA for business schools.

In addition to facilitating the application of the AWA results with full awareness of the test's limitations, management communication specialists should become advocates for a GMAT assessment that is truly relevant for management education and that reflects the most advanced knowledge and practice of writing performance 
assessment. The GMAT essay test, like all large-scale national writing assessments, is based on what many consider to be an outmoded performance assessment model - the timed, writingsample approach that constrains a writer's composing process, truncating it to first-draft writing and isolating it from its social and cultural context. Theory and research on writing, both from cognitive-processing and social perspectives, critique the timed writingsample model of assessment, finding it does not represent any of the current theoretical constructs for writing (Camp, 1993; Purves, 1992; Witte, 1992). Other approaches to writing performance assessment for management development, such as MBA assessments, make an effort to capture the social dimension, but these efforts only partially succeed (e.g., writers responding to a case cannot interact with a manager when planning a document) and they do not allow writers to engage in the full naturalistic writing process (e.g., going back to interview more sources and getting feedback on a draft).

Many researchers in assessment are proclaiming that "the construct of writing assessment is changing" (Huot \& Yancey, 1994, p. 144). Newer assessment models-for example, "portfolio assessments," which involve collecting several types of writing over a period of time; allow for revision, contemplation, and feedback; and also encourage contextual commentary and interpretation by the writer-are superseding timed writing-sample assessments, even for placement at some large universities (Belanoff \& Dickson, 1991; Murphy, 1994). Although not an immediate alternative to such large-scale writing tests as the AWA, portfolio assessments and other types of naturalistic or "authentic assessments" (Black et al., 1994) suggest new possibilities for more fully testing management writing, possibilities that should be explored.

The critical juncture imposed by the implementation of the GMAT performance writing assessment finds management communication faculty confronting a new test of communication abilities that is potentially useful, but one that has serious limitations and critical implications. The AWA challenges communication specialists to become critically aware of the test's appropriate applications, and to use the opportunity to enhance writing assess- 
ment and instruction for management. Exploiting the AWA as the impetus for confronting issues about the place of writing in MBA education, communication faculty can engage other constituencies in a dialogue to facilitate meaningful use and gradual modification of the AWA, while simultaneously working toward the development of a cutting-edge writing assessment, one directly relevant to management education.

The AWA is welcome as a test of critical thinking and analytical writing, and for the attention it brings to writing as a complex and essential management ability. If MBA students are to be equipped to write successfully in MBA programs and in the workplace, however, writing assessment (and instruction in MBA programs) must far exceed the bounds of the GMAT Analytical Writing Assessment.

\section{NOTES}

1. Added to the GMAT in October 1994, the AWA consists of two essays that must be composed in 1 hour. The essays are evaluated holistically by multiple evaluators to produce a single overall AWA score ranging from a low of 1 to a high of 6 . When an individual applies to MBA programs, the AWA score and essays are provided to each school, along with the GMAT scores on the Quantitative and Verbal sections.

2. The GMAT score (combining the Verbal and Quantitative portions, which are also reported separately) excludes the AWA score and is reported to schools in the same fashion as it was prior to the addition of the AWA. Thus, faculty and administrators at each business school must determine the specific purposes, if any, for which they will use the AWA test scores. The independent reporting of the AWA score permits individual schools to ignore the writing test, if they wish, at least temporarily.

3. Although some GMAC survey respondents expressed concern that an essay test might be discriminatory to some MBA applicants (Bruce, 1993), research suggests that indirect language-skills tests might actually discriminate more toward some minority groups, probably because of the emphasis on conventions and usage (Camp 1993; White, 1994).

4. Strictly speaking, the new AWA complements the long-standing indirect test of writing found in the Verbal section of the GMAT. In fact, some research suggests that a combined score may be more valid than direct writing-test results alone (White, 1994). In addition to reporting the separate scores on the writing test and the objective Verbal section, GMAC could eventually report combined GMAT Verbal and AWA scores.

5. Postsecondary national performance assessments of writing include professional school tests and general academic assessments, such as the Scholastic Assessment Test (SAT), formerly the Scholastic Aptitude Test. The Educational Testing Service (ETS), a major player in the development of many national writing tests, as well as the developer of 
the original GMAT (Snook, 1987), collaborated with GMAC on the development of the AWA.

6. Despite the wide acclaim for holistic scoring methods, they have not gone unchallenged. Measurement experts question their reliability (Mehrens, 1992), and writing experts question the effects of the procedures designed to achieve reliability, believing that the constraints on evaluators' natural reading process may achieve reliability at the expense of validity (Huot, 1990). Certainly some of the comments in the GMAC reports tend to create an overly optimistic sense of technical perfection in holistic scoring, suggesting, for example, that discrepant scores are "rare," and consistency from one test administration to the next is assured (GMAC, n.d., pp. 6-7; see Cherry \& Meyer, 1993).

7. The AWA score represents an average of the ratings received on the two essays. In addition, the score for each essay (on the Argument and the Issue) is determined by averaging the independent scores of multiple evaluators. Typically two evaluators rate an essay, but if they award discrepant scores, other evaluators score the essay until adequate agreement is achieved (that is, two scores separated by no more than a single point on the 6-point scoring scale). Outliers are dropped in calculating the scores but are included in calculating reliability (see Cherry \& Meyer, 1993).

8. AWA Score distributions for both local and total candidates are reported to schools with the GMAT summary statistics after each test administration; national statistics on the AWA should become available after a full year of adminstering the writing test. To determine if the locally selected cut-off scores reflect actual needs, GMAC advises that schools should eventually conduct a local validity test of the AWA (GMAC, nd; see Stolzenberg \& Relles, 1985).

9. By making the essays available only to institutions, not to applicants (except those who pay an additional fee), GMAC put the entire responsibility for the diagnostic function of the test on business schools. Of course the essays also represent a potential resource for schools in conducting the admissions process, as noted in the first part of this analysis (Rogers \& Rymer, 1995). MBA faculty or admissions officers could review the writing of the occasional student whose academic record and test scores may be problematic; or use the essays to help make admissions decisions on borderline cases; or review the essays to corroborate international applicants' ability to produce English text.

10. GMAC's survey showed that schools whose students have mean GMAT scores over 500 perceived higher levels of usefulness for the AWA in the admissions process, whereas schools whose students have mean GMAT scores less than 600 (that is, excluding only the "top" schools) perceived the test's usefulness to be in the diagnostic function. According to the GMAC report, "the correlation between responses to these two usefulness questions is a moderate .59 , suggesting that the analytical writing assessment may meet different needs in different schools" (Bruce, 1993, pp. 10-11).

11. Ai some point in the early stages of developing the AWA, GMAC overturned its plan for a writing test of a decade ago and decided against using a case prompt, a task that would have required test takers to compose a management mode of writing (Hecht \& Alloway, 1984). Instead, the AWA was developed around a traditional academic instrument, analytical writing-a general academic writing task that may have seemed to be the most feasible assessment mode for the diverse population of GMAT test takers, whose undergraduate majors and business experiences vary widely (Rogers \& Rymer, 1995). 


\section{REFERENCES}

Belanoff, P., \& Dickson, M. (Eds.), (1991). Portfolios: Process and product. Portsmouth, NH: Heinemann Boynton/Cook.

Black, L., Helton, E., \& Sommers, J. (1994). Connecting current research on authentic and performance assessment through portfolios. Assessing Writing, 1, 247-266.

Bruce, G. D. (1993). Attitudes toward the addition of an analytical writing assessment to the GMAT: Results of a survey of institutions using the GMAT. Available from Graduate Management Admission Council, 2400 Broadway, Suite 2030, Santa Monica, CA 90404.

Camp, R. (1993). Changing the model for the direct assessment of writing. In M. M. Williamson \& B. A. Huot (Eds.), Validating holistic scoring for writing assessment: Theoretical and empirical foundations (pp. 45-78). Cresskill, NJ: Hampton Press.

Cherry, R. D., \& Meyer, P. R. (1993). Reliability issues in holistic assessment. In M. Williamson \& B. A. Huot (Eds.), Validating holistic scoring for writing assessment: Theoretical and empirical foundations (pp. 109-141). Cresskill, NJ: Hampton Press.

Faigley, L., Cherry, R. D., Jolliffe, D. A., \& Skinner, A. M. (1985). Assessing writers' knowledge and processes of composing. Norwood, $\mathrm{NJ}$ : Ablex.

GMAC (Graduate Management Admission Council). (n.d.; distributed 1994, May). The GMAT analytical writing assessment: An introduction. Santa Monica, CA: Author.

Hecht, L. W., \& Alloway, S. S. (1984). Developmental and operational plans for the graduate management writing assessment. Princeton, NJ: Graduate Management Admission Council \& Educational Testing Service.

Huot, B. (1990). Reliability, validity, and holistic scoring: What we know and what we need to know. College Composition and Communication, 41, 201-211.

Huot, B., \& Yancey, K. B. (1994). From the editors. Assessing Writing, 1, 143-145.

Mehrens, W. A. (1992). Using performance assessment for accountability purposes. Educational Measurement: Issues and Practices, 11(1), 3-9, 20.

Murphy, S. (1994). Portfolios and curriculum reform: Patterns in practice. Assessing Writing, 1, 175-206.

Purves, A. C. (1992). Reflections on research and assessment in written composition. Research in the Teaching of English, 26, 108-122.

Quellmalz, E. S. (1984). Toward successful large-scale writing assessment: Where are we now? Where do we go from here? Educational Measurement: Issues and Practice, 3(1), 29-32, 35.

Rogers, P. S. (1994). Analytic measures for evaluating managerial writing. Journal of Business and Technical Communication, 8, 380-407.

Rogers, P. S., \& Rymer, J. (1994, November). The new GMAT writing test: A critical analysis. Paper presented at the meeting of the Association for Business Communication, San Diego, CA.

Rogers, P. S., \& Rymer, J. (1995). What is the relevance of the GMAT Analytical Writing Assessment for management education? Management Communication Quarterly, 8, 347-367.

Smith, W. L. (1993). Assessing the reliability and adequacy of using holistic scoring of essays as a college composition placement technique. In M. M. Williamson \& B. A. Huot (Eds.), Validating holistic scoring for writing assessment: Theoretical and empirical foundations (pp. 142-205). Cresskill, NJ: Hampton Press. 
Snook, J. L. (1987). The history of GMAC. In Admission Office Management: A Guide to Professional Practice (pp. 3-11). Los Angeles, CA: Graduate Management Admission Council.

Stolzenberg, R. M., \& Relles, D. A. (1985). Calculation and practical application of GMAT predictive validity measures. Los Angeles, CA: Graduate Management Admission Council.

White, E. M. (1993). Holistic scoring: Past triumphs, future challenges. In M. M. Williamson \& B. A. Huot (Eds.), Validating holistic scoring for writing assessment: Theoretical and empirical foundations (pp. 79-108). Cresskill, NJ: Hampton Press.

White, E. M. (1994). Teaching and assessing writing. San Francisco: Jossey-Bass.

Williamson, M. M. (1993). An introduction to holistic scoring: The social, historical, and theoretical context for writing assessment. In M. M. Williamson \& B. A. Huot (Eds.), Validating holistic scoring for writing assessment: Theoretical and empirical foundations (pp. 1-43). Cresskill, NJ: Hampton Press.

Witte, S. (1992). Context, text, intertext: Toward a constructivist semiotic of writing. Written Communication, 9, 237-308.

Priscilla S. Rogers and Jone Rymer's collaborative work currently includes a research project comparing modes of performance assessment of managerial writing and a casebook entitled Strategic Cases for Business and Management Communication. Rogers's research focuses on developing tools for assessing management messages. Recent publications present analytic measures and an evaluative instrument called the "Competing Values Framework." An associate professor at the University of Michigan, Rogers founded and directs the MBA Writing Program, which includes a writing assessment, consulting services, and management communication courses at the university's School of Business. Rymer's research includes assessment and case pedagogy. Among her publications on these topics are several articles and a text, Cases for Technical and Professional Writing (with B. Couture). An associate professor at Wayne State University, Rymer was recently a visiting professor at the Anderson Graduate School of Management at UCLA, where she worked on writing assessment and began an extended genre study of the case report (with J. Forman). 